\title{
Correspondance de Russie
}

Faculté d'histoire de l'Université de Moscou année 1999-2000

Andreï Tyrsenko

\section{OpenEdition}

Journals

Édition électronique

URL : https://journals.openedition.org/ahrf/1981

DOI : 10.4000/ahrf.1981

ISSN : 1952-403X

Éditeur :

Armand Colin, Société des études robespierristes

Édition imprimée

Date de publication : 1 septembre 2001

Pagination : 151-152

ISSN : 0003-4436

Référence électronique

Andreï Tyrsenko, «Correspondance de Russie », Annales historiques de la Révolution française [En ligne], 325 | juillet-septembre 2001, mis en ligne le 10 avril 2006, consulté le 24 avril 2022. URL : http:// journals.openedition.org/ahrf/1981; DOI : https://doi.org/10.4000/ahrf.1981

Ce document a été généré automatiquement le 24 avril 2022

Tous droits réservés 


\section{Correspondance de Russie}

Faculté d'histoire de l'Université de Moscou année 1999-2000

\section{Andreï Tyrsenko}

Le cours pour spécialistes de Serge Aberdam

1 Du 15 septembre au 12 octobre 1999, Serge Aberdam était invité pour un cours destiné aux étudiants francophones spécialisés en histoire de France, sur les chantiers actuels de recherche en histoire de la Révolution française. Entre autres questions abordées dans ce cours, Image et opinion en histoire, le cas du Bicentenaire..., les collections, la politique, l'opinion (à partir d'objets d'art de différentes origines, savantes et populaires), la cartographie et l'histoire révolutionnaire (cartographie d'époque et cartographie moderne), la Révolution et les élections...

2 Dans son cours ainsi que dans sa communication faite à la conférence organisée pour les historiens russes, Serge Aberdam a présenté les recherches en cours dans le domaine des élections de l'époque révolutionnaire, en s'appuyant sur ses propres analyses. Il a envisagé les élections comme une forme majeure de la sociabilité politique de l'époque révolutionnaire, avec les particularités des données (vote par assemblées, difficultés de l'évaluation du nombre des citoyens) et l'objectif d'obtenir des résultats représentatifs au niveau national, puis d'établir et de juxtaposer les cartes de la géographie électorale sans évacuer les contingences, par exemple saisonnières, qui influencent la participation électorale (les votes de 1792, 1793 et 1795 ont eu lieu en pleine récolte).

Soutenance de travaux sur la Révolution française

3 Les sujets des diplômes de fin d'études supérieures attestent la diversité des problématiques explorées. Deux diplômes soutenus sont consacrés à des groupes politiques de l'époque révolutionnaire. Le premier, «Mallet du Pan et le groupe des monarchistes constitutionnels" (V. Sérguienko, dir. D.Bovykine), traite les représentations politique de ce groupe dont faisaient également partie Malouet, LallyTollendal, Montlosier. L'auteur conclut à l'existence d'un groupe uni par l'affinité des représentations politiques et marqué par son caractère antirévolutionnaire. Le second travail, intitulé «La société de 1789. Les hommes et les idées» (A. Demianov, dir. A.Tyrsenko), étudie la prosopographie, le discours politique et la pratique 
parlementaire de la Société de 1789. L'auteur conclut à l'existence d'un système de représentations politiques qui déterminait l'identité de ce groupe et servait de base à sa pratique parlementaire.

4 Le diplôme de M. Zaharova (dir. D. Bovykine), "Les notions-concepts du lexique de Robespierre et de ses partisans ", est consacré aux notions-concepts de : "révolution », « république », « monarchie », « liberté », « tyrannie », « dictature » ... L'auteur en vient à la conclusion qu'à l'époque du gouvernement révolutionnaire les Robespierristes n'ont pas eu le temps d'élaborer un programme cohérent ce qui explique leurs divergences. Enfin le diplôme intitulé «S. T. Coleridge et la Révolution française » (N.Kornopeleva, dir. A. Tchoudinov) aborde le problème de l'Image de la Révolution française chez un contemporain. L'auteur montre comment la perception de la Révolution par Coleridge a évolué de l'enthousiasme révolutionnaire (Ode à la prise de la Bastille) au rejet absolu des mesures violentes destinées à la réalisation d'idéaux abstraits. 